THE HERMITE ELECTROLYTIC PROCESS AT POPLAR I9I

\title{
DISCUSSION.
}

Mr. J. B. C. Kershaw (communicated) : Mr. Biggs has made strange mistakes in his quotations from my article in Electrochemical and Metallurgical Industry (April, I906), and I must therefore ask to be allowed to give the correct version of the introductory passage from which he has gathered his extracts :-

"The electrolysis of solutions of the alkali metal chlorides always produces chlorine at the anode, and the hydrate of the base (sodium, potassium, or magnesium) at the cathode. In the electrolytic alkali processes the aim of the inventor has been to effect removal of these products before they can react one with the other. In the electrolytic bleaching and disinfecting processes the chlorine and the caustic hydrate are allowed to react, in order that the chemical changes represented by the following equations may occur :-

"( (I). $3 \mathrm{NaOH}+6 \mathrm{Cl}=3 \mathrm{NaOCl}+3 \mathrm{HCl}$ (sodium hypochlorite and hydrochloric acid).

"(2). $3 \mathrm{NaOH}+{ }_{3} \mathrm{HCl}=3 \mathrm{NaCl}+{ }_{3} \mathrm{H}_{2} \mathrm{O}$ (sodium chloride and water).

"If the temperature be allowed to rise above a certain point, $120^{\circ} \mathrm{F}$., a further chemical action will occur, and chlorate will be produced. It is, therefore, necessary in all electrolytic bleaching and disinfecting processes to pay great attention to the temperature, as chlorates are useless for bleaching purposes.

"The production of hypochlorite solutions for bleaching and disinfecting purposes by means of electrolysis has undergone little development in the United Kingdom, and only two types of cell are known to the writer to be at present in operation, namely, the Vogelsang and the Atkins cells.

"Early in the nineties a considerable amount of money was expended, however, upon experimental trials with the Hermite cell for sewage purification and sterilisation, and much attention was given to the results of these trials. The failure to establish this method of sewage treatment upon a commercially sound basis led to the bankruptcy of the firm financing these trials, and to a collapse of interest in all processes and cells for producing by aid of electrolysis a solution containing free chlorine for bleaching or disinfecting purposes. It is only lately that attention has again been given to this subject of sewage disinfecting and sterilisation in the United Kingdom, the proposal of the Medical Officer of Health for Poplar to use electrolytic hypochlorite for disinfecting purposes within the borough having aroused considerable interest.

"The low price at which hypochlorite of lime, or 'bleach,' is now selling in the United Kingdom ( $£_{4}$ Ios. per ton), is likely, however, to hamper the extension of these processes, for it is more than doubtful whether any of them can compete in price with the older bleaching agent. For certain 
purposes, hypochlorite of soda is much to be preferred to hypochlorite of lime, the active agent in bleaching powder; and in these cases the higher cost of the former, even when produced by the electrolysis of brine, is unlikely to retard its utilisation as soon as a cheap, reliable, and durable electrolytic cell for producing it is placed upon the market. The Hermite cell and process in its original form did not fulfil these conditions, and the same judgment must be passed upon many of the patented forms and processes which have succeeded it. Even with cheap power and a durable and reliable cell, electrolytic hypochlorite is unlikely to take the place of bleaching powder for ordinary bleaching purposes, until the price of the latter has advanced to over $£ 6$ per ton, and therefore the development of this industry is somewhat doubtful in countries where bleach is manufactured in large quantities, by either the old Le Blanc or newer electrolytic processes."

The figures given in Mr. Biggs's Paper support the opinion expressed in the final sentences of the above paragraph. With electricity at Id. per unit (which by the way is less than it costs to produce in Poplar) $3.36 \mathrm{kgs}$. of active chlorine are obtained with an expenditure of eleven shillings. Taking bleaching powder at its present price, and allowing $f_{i}$ per ton for freight and labour charges, eleven shillings would purchase ten times this amount (or $35 \mathrm{kgs}$.) of active chlorine, in the form of calcium hypochlorite. Even allowing for the superior efficiency of the sodium magnesium salt as a sterilising agent, it is impossible to believe that there can be any economy in paying eleven shillings for what could be purchased for less than two. The Hermite sterilising installation at Poplar is simply therefore yet another instance of the foolish waste of money by municipal bodies in general, and by Poplar in particular.

Mr. Biggs, in p. I of his Paper, states that the Poplar installation is efficient. A comparison of the yield with that obtained in other forms of hypochlorite cell shows, however, that Iro E.H.P. hrs. are required to produce I kg. of active chlorine, and that the efficiency is only $21.5 \%$, as compared with a power consumption of 6.57 E.H.P. hrs. and efficiency of $35^{\circ} 9 \%$ for the latest and best form of hypochlorite cell.

In closing this contribution to the discussion upon Mr. Biggs's Paper, I may perhaps state that $I$ am as keenly interested as the author in all electrochemical developments of a sound character, but that I am not anxious to see extensions of the industry similar to that initiated by Dr. Alexander at Poplar, since these in the long run only end in failure, and place hindrances and difficulties in the path of progress in other directions.

Dr. R. S. Hutton : The general description of the Poplar hypochlorite plant is certainly of much interest, but it is to be regretted that the author has only given the most vague description of the data likely to be of the chief interest to the members of this Society. In the hope that he will see his way to supplement his Paper in this direction and thus considerably enhance its value, I venture to ask for information on the following points :-(I) Size and shape of electrodes and troughs. (2) Diameter and length of platinum wire on each anode. (3) System adopted for making the terminal connections to the electrodes. (4) Durability of the zinc cathodes. (5) Method employed to prevent the formation of an incrustation of magnesium hydrate or hydrated salts on the cathodes.

In trying to collate the results of this process according to the system which is almost universally adopted in connection with hypochlorite plants, I have been pleasantly surprised to note the great improvement which has been 
effected since the Hermite process was first exploited in this country. From the data which are given it is, however, almost impossible to tabulate a complete record, and I feel sure many members would be grateful if the author would fill in the numerical values in the following lines, taking into consideration as far as possible the average results obtained at Poplar.

- grams active chlorine per litre.

- K.W.H. (B.T.U.) per I kilo active chlorine.

- kilos salt $\left(\mathrm{MgCl}_{2}+\mathrm{NaCl}\right)$ per I kilo active chlorine.

Concentration of electrolyte - kilos salt per roo litres.

Current efficiency - per cent.

In Appendix A the author does not mention that Mr. Kershaw's article professes to deal solely with the use of hypochlorite as a sewage sterilising agent. No account has been taken of the vast amount of work done on the Continent, and so ably summarised in Engelhardt's monograph, "Hypochlorite und elektrische Bleiche" (Halle: W. Knapp, I903), a book of 273 pages, containing invaluable data from the technical investigations of Kellner, Oettel, and numerous other active workers in this field.

In considering Appendix B, I cannot resist the temptation of again referring to Continental work. Professors F. Foerster and E. Müller, of Dresden, devoted a number of years to a detailed study of the chemical and electrochemical actions occurring in the electrolytic production of hypochlorites and have given an excellent résumé of their work ( $Z$. fiir Elektrochemie, 1903, 9. I 7 I and 195).

Finally, in Appendix D no account is taken of the cost of the caustic soda additions mentioned in an earlier section of the Paper, and the question of depreciation is surely not covered by the low rate of interest allowed in the capital expenditure. In view of the increasing interest which is being taken in this country in the electrolytic production of hypochlorites, and the evident importance of the new Hermite plant at Poplar, I trust the author will excuse my request for so many further details.

In reply to Mr. Kershaw's criticisms on the efficiency of the Poplar cell, Dr. Hutton pointed out that efficiency depended largely on the concentration of the solution; it was not possible to maintain a high efficiency with solutions of such a low concentration.

Dr. F. W. Alexander, the Medical Officer of Health for Poplar, stated he was not a chemist nor an electrician, nor had he any financial interest in the Hermite process; he had simply taken up the subject from a scientific point of view. He had not benefited in any way by it and did not expect to do so; he had worked for the love of the matter and he had no axe to grind. Were we living in the days of Galileo? He was astonished to think that in the nineteenth century every possible obstacle had been placed in his way through certain articles in the press advising his Council not to listen to him as the process had been a failure in the past and could not possibly be of any use, it would be waste of public money, and was simply a fad of the Medical Officer. If the process had been of any use it would have come into operation before. However, he had had the matter in his mind for many years since the publication of the report of the Lancet Commission, and had worked at the subject for nearly two years ; the working of the apparatus in Poplar was a complete success-it had come to stay-and it had gone quite beyond his expectations. No doubt the failure of the past had been due to the want of stability of the fluid, but this had now been got over, as is seen by Stability Tables I and 2 of the Paper, and the samples referred to in Table 2, be it remembered, were some of the first made before the use of the stirrers. It 


\section{I94 THE HERMITE ELECTROLYTIC PROCESS AT POPLAR}

was prophesied in the press that the formation of the oxychloride would choke or block the zinc electrodes, and that scrapers had been used in the past, but he would speak on this matter later on as to how the oxychlorides were dealt with.

It was also stated that chloride of lime would be better to use. $\mathrm{He}$ wanted to know how this substance could be bottled and given out to the public; one would have to mix it with water to dissolve out the calcium hypochlorite, and as the commercial powder contains $3^{0}$ to 38 per cent. of available chlorine, the waste lime would have to be disposed of, and all this meant labour, and, moreover, chlorinated lime solutions will destroy fabrics sooner than hypochlorites of soda or magnesia.

As to the cost of making the fluid, in Poplar the apparatus had been running since the end of January, a period of ten months, during which time there had been required 2,288 units of electrical energy at $I \frac{1}{2} \mathrm{~d}$. per unit, amounting to $f_{15}$, not quite four tons of salt had been used at $24 \mathrm{~s}$. a ton, amounting to $f_{4} \mathrm{r} 6 \mathrm{~s}$., not quite two tons of chloride of magnesium at $£ 3$ i7s. 6d. per ton had been used, amounting to $£ 7$ i5s., the cost of the caustic soda was about $£_{2}$ Ios., and water $£_{2}$, making a total of $£_{32}$, and this sum included material in hand. This expenditure did not include the labour, which really was less than in the old days when carbolic acid was bottled and bags were filled with carbolic powder and distributed to the public. $\mathrm{He}$ would speak later on with respect of this labour question. Now for the sum of $£ 32$, including material in hand, the Public Health Department had been supplied with disinfectant fluid against an expenditure of $£ 313$ for the year I905, and, moreover, in the Works Department the roads, with the marketplaces, in the parish of Bromley had been watered with the fluid, and now the Sick Asylums at Poplar and Bromley were being supplied, also the Workhouse and all institutions inside and outside the borough belonging to the Guardians. Surely this was success whatever the detractors of the process might say, and all this for the sum of $£ 32$.

With respect to the watering of the roads and market-places, the watercarts in Poplar had a capacity of 400 gallons, and on the top of each cart had been fixed a small tank to hold I $_{5}$ gallons of the electrolysed fluid. Five gallons of this fluid were added to each 400 gallons of water, giving a strength of 0.05 grammes of chlorine per litre. He had based this strength on a statement of Dr. Rideal that in "Experiments conducted by Professor Robinson, Dr. Kanthack, and myself a bad effluent was treated with one or two parts of chlorine per 100,000 with very satisfactory results as regards bacteria."

Now as to the working of the apparatus one man only is required, and he not a skilled one, merely an ordinary intelligent individual, at $35 \mathrm{~s}$. per week. $\mathrm{He}$ attends to the charging and working of the apparatus and the testing of the fluid, and keeps a $\log$ of each day's work and distribution. It is true there is another man at the depôt with wages of 30 . per week. This man is engaged in bottling and delivering the fluid for distribution, and he is also quite capable of looking after the apparatus. Formerly in the fluid and carbolic acid powder days during the busy time six or seven men were at work.

The object of the Medical Officer was to make the working of the apparatus of such a nature as to be simple and automatic and not to require the constant attention of a skilled person, who would receive a high salary, and men to do the labour work, which would increase the cost of the output. The objects aimed at were as follows :--

I. To see at a glance whether the apparatus were working properly. This is accomplished by a gauge glass in front of the large tank and another gauge 
glass on the little supply tank, the first to show the quantity of salt liquor capable of being acted upon, and the second to show if the liquor is running properly into and out of the small supply tank, as the chloride of magnesium contains impurities which are likely to block up the valve of the small cistern and the taps leading to and from the same. A thermometer is kept in the small supply tank to see the temperature of the salt liquor, and another thermometer is placed at the outgo of the last electrolyser; the difference of the temperatures will give a measure of the electrical heat, which is found when the apparatus is working satisfactorily to be under $30^{\circ} \mathrm{F}$. The small tank is necessary to keep an unvarying flow of the fluid into the electrolysers. When first the apparatus was erected the fluid used to become unduly hot on account of the flow slowing down through the diminution of the head of water in the large tank. This tank had ultimately to be raised on two girders and a small supply tank fixed at a lower level.

2. The liquor to be electrolysed in the large tank has to be stirred from time to time to keep the mixture of an equal gravity throughout, more especially as for obvious reasons a certain quantity of a solution of sodium hydroxide is added. To keep the liquor stirred a large broad drilled plate of galvanised iron is used, one end of which acts as the fulcrum when the other is lifted up by means of a chain leading over pulleys to the ground, so that the attendant has only now and again to pull the chain to lift the plate up and down instead of running up and down the ladder and stirring the liquid with a rod.

3. It is necessary to govern the electric current, especially as the depott is so near the electricity works and the current is taken off direct from the mains, and also on account of the density of the salt mixture to be acted upon varying from time to time, no doubt due to the temperature changes of the air, for the more sodium and magnesium in the liquor the greater is its conductivity. This difficulty is got over by the current regulator.

4. To prevent shocks and waste of fluid whilst changing the carboys a special glass tap has been made.

5. To prevent loss of available chlorine the solution of sodium hydroxide drips into a specially blown carboy at the same time as the fluid is running into it, and the two fluids are mixed with a stirrer inserted through an aperture in the neck of the carboy, and when the carboy is full a final mixing for about two minutes is given by means of a stirrer fixed to gear wheels. Before the ebonite stirrers with rubber flaps were made, full carboys and half carboys had to be shaken rapidly for ten minutes, and this not always with the best results as to bringing about the desired stability, for when sodium hydroxide is added the precipitate falls to the bottom, and it is necessary to render the solution milky throughout.

Dr. Alexander stated that no doubt the instability of the fluid was due to the salt in the fluid. M. Hermite made a fluid for medical purposes called "Hermitine," which had the salt taken out of it by a secret process, and thereby the fluid was rendered practically absolutely stable, so much so that it was not kept in amber-coloured bottles, but for disinfecting purposes the fluid made at Poplar was of course stable enough. The plant at Netley was still running satisfactorily, but in that case a stable form of hypochlorite was not required.

6. So far as oxychlorides are concerned the apparatus in ten months had only been taken to pieces and cleaned twice. Every day after working the electrolysers are emptied by means of the mud-holes by removing the rubber plugs, and the fluid which is run out is kept to recharge the electrolysers. The electrolysers after being emptied are washed by means of a hose, and 


\section{I96 THE HERMITE ELECTROLYTIC PROCESS AT POPLAR}

then until the next working are kept filled with water, which softens any deposit which forms upon the electrodes, and before starting work the electrolysers are emptied and washed out again, a matter which takes up a few minutes every day before and after each working.

Dr. Alexander mentioned he had seen an exceedingly simple apparatus in M. Hermite's factory at Rolleville which makes a solution of hypochlorite of magnesia at ro grammes of chlorine per litre, and it was a very easy matter on the same lines to make it at 50 grammes per litre, but he of course could not give details to the Society, as the apparatus was shown to him in confidence.

He thanked Mr. Bowden, the chief electrical engineer to his borough, for the kindly words of cheer which he gave him during the exceedingly trying time when he was endeavouring to make the apparatus work simply and automatically, and to render the fluid stable by simple means, so that he could justify himself for having recommended his Council to expend public money for such a venture.

In conclusion, whatever the detractors of the process might say, there was no doubt in his mind the process had now come to stay, as it was obvious in these days of cheap electricity nothing could be better for a sanitary authority than to possess a simple automatic apparatus which has a tap to be turned on at any moment to deliver a cheap and efficient disinfectant composed of oxygen and chlorine.

The members were invited to inspect the apparatus.

Dr. S. Rideal, both as a chemist and bacteriologist, said that he had had a good deal to do with the various electrolytic processes, and had an opportunity many years ago of carefully studying the Hermite process when installed at Worthing, and since that date at Netley. Later, in conjunction with Professors Kanthack and Robinson, he carried out a series of experiments at Maidenhead with the electrozone process, and there established the conditions for successful sterilisation of sewage effluents. More recently still he had examined the Atkins plant, which had for some time been in operation in connection with the sewage works at Guildford, and he had there confirmed the results earlier obtained at Maidenhead, and had satisfied himself that electrolytic chlorine was not only capable of sterilising sewage effluents after bacterial treatment, but could be advantageously employed for reducing the odours from septic tanks and from sludge when necessary.

Quite apart from sewage sterilisation there was a wide field of application for hypochlorite, provided it could be made economically, and he quite supported the claims made by Dr. Alexander for electrolytic chlorine as against bleaching powder, even when the former was more expensive. The convenience of being able to make the fluid on the spot-to turn on the tap so to speak-as required, and the absence of transit difficulties weighed more strongly than cost for ordinary disinfecting requirements, and there was no doubt that it would be more largely used as its value became known. He had a high opinion of the value of watering streets with a sterilising fluid, as the germs in dry horse refuse and other dust were certainly sources of danger ; indeed the dust nuisance caused by motors now rendered the use of a sterilising fluid a necessity for street watering. Cost, therefore, was by no means an all-important consideration, and in any case the cost of electrolysis was quite small. The early processes were costly chiefly on account of the material ; for street watering some material had to be used, and this factor was therefore negligible.

In sterilising the cost was made great on account of the large amount of undecomposed salt present. The most successful cell gave a maximum 
amount of free chlorine from a given quantity of salt, and it was in this that the early cells fell short. An incidental disadvantage of undecomposed salt in certain cases was that it must not be introduced into drinking water. Stability, as had been pointed out, was an important quality, but it was difficult to say exactly on what it depended; the temperature of formation was not the only factor, he thought that it depended rather on the quantity of alkali present.

Mr. Lewis A. Smart said that the process particularly appealed to him, as he looked at it from the point of view of a consulting engineer, who had to design and control central electric power stations. The great trouble with power stations, particularly if the load is largely a lighting one, is to get a high load factor. It appeared to him that processes such as this would have a beneficial effect on the load factor, and consequently on the cost of electricity to the consumer, especially if the enterprise belonged to the same people as the power station, and within certain limits, was under the control of the station engineer, as then, when the peak of the load was reached, the electrolytic process could be cut out for an hour or two, though in the case of the manufacture of hypochlorite, the load would presumably only be required between the hours of 6 a.m. and 6 p.m., so would not come on during the hours when the peak of the load curve was generally reached. Mr. Smart's only regret was that the process did not consume more power, and he believed that the Society would be doing yeoman service to mankind in general, and to public supply engineers in particular, if it could draw attention to electrolytic processes which could be remuneratively adopted by power station owners, and utilise current during the hours when the lighting load was small.

Mr. Wolf Defries said that in comparing the cost of hypochlorite with that of chloride of lime it must not be forgotten that although the two materials would be on a level as regards variations in prices of raw material, the former always contained an element of cost due to current, and this had a tendency to decrease as time went on. The future, therefore, would favour electrolytic hypochlorite rather than bleaching powder. But, as had rightly been pointed out, the ultimate cost-to the consumer-depended on how the product was to be utilised, and questions of convenience, ease of transport, and so forth, became in many cases determining factors. In his opinion Dr. Alexander had performed a public service in taking up and developing a process that seemed so unattractive, and was certainly so unpopular when he first adopted it to meet his own special requirements.

Mr. C. V. Biggs (communicated reply): I am obliged to Mr. Kershaw for calling my attention to an error in Appendix A. The repetition of the word "hypochlorite" in the original attributed to him sentiments chemically indefensible, and the paragraph has been altered accordingly.

Mr. Kershaw's contention that the use of hypochlorite solution as made by the Hermite process is inefficient has been dealt with by Dr. Hutton, Dr. Rideal, and Dr. Alexander. The generation of electricity from coal is also an inefficient process, but it is convenient and expedient.

$\mathrm{Mr}$. Kershaw remarks that Id. per unit is less than the cost of production at Poplar. The latest quotation for power in bulk there is $0.85 \mathrm{~d}$. per unit.

With regard to Dr. Hutton's request for more precise information as to the cells, I did not consider it fair to the makers to take exact measurements. From memory I should say that the electrodes measured about ro in. $\times 3$ in. Each trough contained ten cells (one positive and two negative plates each) and an end compartment, being 4 feet long, over all. The platinum wire on the positive appeared to be of 20 S.W.G. This would suppose 30 wires 


\section{I98 THE HERMITE ELECTROLYTIC PROCESS AT POPLAR}

in parallel to each positive plate with an average length of I foot. These wires were connected to a terminal screwed into the plate.

To obviate incrustation on the cathode the cells are washed out with water after each run.

The average grammes per litre obtained with 16 amps. at Poplar from the data taken is 4.5 .

K.W.H. per I kilo of chlorine (at 16 amps.) $=7 \cdot 2$. Kilos salt per kilo active chlorine $=13.5$.

The calculations for this are given below.

20 litres of saturated solution of $\mathrm{MgCl}$ contains ro $\mathrm{K}$. salt.

$$
\begin{aligned}
& \text { I00 " " } " \quad \mathrm{NaCl} \quad \text { " } 40 \mathrm{~K} \text {. " } \\
& 40+10=50 .
\end{aligned}
$$

840 litres at 4.5 per litre $=3,780$

$$
\begin{aligned}
& =3.7 \text { kilos. } \\
\frac{50}{3.7} & =13.5
\end{aligned}
$$

Concentration of electrolyte :-

Kilos salt per roo litres $=\frac{5^{\circ}}{9^{\circ} 07}=5^{\circ} 5$.

I am obliged to Dr. Hutton for calling attention to that admirable work of reference, V. Engelhardt's "Hypochlorite und elektrische Bleiche." This work was quoted from in the Paper read before the Society on October $3 \mathrm{I}, 1905$, and is doubtless well known to the members. 